\title{
Medieval Worlds: Introduction to the First Issue
}

Books, web-sites or university courses entitled `The Medieval World « usually deal with Medieval Europe, sometimes only with its >Latin journal, >Medieval Worlds`, underlines the diversity of our global past, while maintaining that common approaches are possible. 'Global History often concentrates on the contemporary and modern history of a globalized world; but global perspectives on pre-modern periods are also possible before or beyond processes of globalization. Many fascinating projects explore wide horizons of the global past, both temporally and spatially. These new lines of research depart from many disciplines and reach out across disciplinary divides; arguably, this is one of the most dynamic fields in the heterogeneous academic landscapes of the study of the past. For those who are interested in engaging with current developments and advances in this type of research, however, it is still hard to get an overview of its progress. The present journal is intended to become one of the intellectual "hubs " in this regard: exploring new approaches, stimulating comparative research, offering methodological debates, exchanging reports across disciplines, and presenting current large-scale projects.

The journal's name, >Medieval Worlds - Comparative and Interdisciplinary Studies`, is programmatic in several ways. Within broader debates of the Social Sciences and Humanities, the Middle Ages often are conspicuously absent, or figure as a simplified counterfoil against modernity. Therefore, the journal aims to help putting Medieval Studies on the map. We use smedievalı as a rough chronological indication, which can be modified according to regional and disciplinary research traditions, and which should in any case include late antique and early modern periods of transition. The journal does not advocate any sstrong c concept of sthe Middle Ages as a period defined by particular characteristics, which would hardly be tenable in a global context. We do not depart from any teleological idea which would limit the field and impose a choice of one explanatory model over another. Scholars may legitimately debate when axial or post-axial ages led to fundamental transformations across Eurasia, or whether or not the Middle Ages marked the beginning of a >Great Divergencer. The journal can host such discussions, but does not regard them as an obligatory starting point for research on the wide varieties of medieval forms of life. Medieval societies should not simply be studied as stages in a process that only became meaningful later. There is more to the Middle Ages than merely representing a prehistory of modernity - i.e. of the modern individual, state, nation, democracy, media, economy, or globalization. »Other " socio-cultural histories first have to be studied in their own right. Only thus can they contribute to a more general understanding of long-term social and cultural dynamics. In this way, they also may shed additional light on the inherent mechanisms of present-day societies.

Studying medieval worlds requires a critical caveat regarding Eurocentrism. Traditional world histories basically recounted how Europe unified an originally multiple world, first militarily and politically and then economically and culturally. Now, finally, a global view of history is gradually replacing Eurocentric perceptions of the past, not without controversial debates. The problem is not only that European history was often regarded as central to world history, but that the history of other regions was approached with a conceptual apparatus developed with regard to Europe. Post-colonial studies and the decons- 
truction of generalized 'European them too far creates another set of problems. Certainly Europe should not serve as a sstandard of comparison. However, we should not simply abandon the research tools and the critical approaches that the disciplines involved have developed and refined over a long time, but strive for a carefully balanced and transparent approach. In addressing >medieval worlds (in the plural), we wanted to stress the multiplicity of the medieval universe without essentializing its cultural differences.

The focus of the journal is on comparative studies and reflections. The challenge here is to find ways of doing comparative history that do not depart from preconceived models or units, and thus avoid essentializing cultural or other objects of comparison. Issues of comparison are addressed in a growing body of methodological literature, together with a number of innovative propositions and designs: these have ranged from qualitative comparison in its basic dimensions to various forms of middle-range comparison, from sthick « comparison across comparing networks and comparison by sbig datar quantifications up to scomparing the incomparabler. Both the theoretical framework and, perhaps even more importantly, pragmatic methodologies of some among the more promising of these endeavours wait to be further differentiated, refined, exemplified, and developed. The first issue of >Medieval Worlds s is intended to contribute to these efforts, both from theoretical and from pragmatic angles. In some of its social science legacies in the narrow sense, comparison has been linked to general and transhistorical concepts. From the outset, this frequently was intended to establish general models or typologies. That is a legitimate social-science approach that can provide fundamental impulses for research. Yet we also need genuinely processual and historical methods that allow to historicize our concepts, and to address issues of middle-range comparison. >Medieval Worlds explicitly invites source-related research as long as it can be used to address comparative issues. These efforts can then provide a basis for further modelbuilding in dialogues with scholars from all historically engaged academic disciplines.

What makes comparative historical studies so fascinating, but also difficult, is the multiplicity of disciplinary approaches that one needs to take into account: the disciplines of Historical Studies, Socio-Cultural Anthropology, Sociology, Religious Studies, Archaeology, Philological and Literary Studies, Linguistics, History of Art, Cultural/Transcultural Studies and others; and within them, various fields and schools that also diverge in their methods and approaches. Scholars from many of these research environments have already made substantial experiences in interdisciplinary research. Yet this still presents a challenge. To put it bluntly, the more you know about the cases to be compared, the more difficult does it get to establish clear distinctions and convincing typologies. This can also be exemplified by the experience of the editors. >Medieval Worlds « was created by an interdisciplinary team including medieval historians of Europe, social anthropologists combining field-work with the study of historical sources, scholars of Islam and of (philological and cultural) Asian Studies working in a joint long-term project, >Visions of Community< (VISCOM, see the presentation in this issue). Work in the VISCOM project started with the experience that scholars from different disciplines often speak different languages even when they use the same terms and concepts, and in occasional contact rarely realize that. It is therefore essential to develop an in-depth understanding of the sources, the problems of their interpretation, and the established approaches and paradigms in the different fields and disciplines involved. Comparative and interdisciplinary studies should go beyond using each other's results and conclusions, and be more attentive to the intricacies of disciplinary work with the sources and to the con- 
ceptual tools current in other fields. The first issue of >Medieval Worlds addresses problems of methodology and presents approaches by senior scholars that will hopefully encourage both senior and junior scholars to propose their own studies in future issues.

>Medieval Worlds areas of global history. The journal proposes a more specific design to accommodate diversity, comparison, and debate. The online, open-access format allows a more flexible, tothe-point collaboration between different fields and disciplines than previously possible. We would like to promote a better understanding of the problems of interdisciplinary exchanges, and ultimately enable a gradual convergence of scholarly languages. Therefore, we will offer the following formats for publication:

* Comparative articles by individual authors or clusters of articles by groups of authors, provided that they represent different disciplines or approaches, or address different macro-regions. >Medieval Worlds` will be open to regular submissions on comparative topics.

* Thematic issues ranging across different fields and disciplinary boundaries, announced by the editors by means of a call for papers, or also proposed as a whole by groups of authors.

* Presentations of larger comparative projects and their results and review articles addressing relevant issues or current debates in comparative medieval studies. At least initially, there will be no reviews of single publications.

* A specific format will allow searching for matching or complementary studies from different fields. Papers that address topics relevant for comparison can be submitted for a call for (a) matching paper(s) from other fields. For this purpose, a discussion forum has been set up on the website http://medievalopen.oeaw.ac.at : 'Medieval Open can serve to put people working on related topics in different academic environments in touch with each other, and provide a moderated forum for debate and for developing comparative perspectives. Additionally, a search for matching articles can also involve the Advisory Board of the journal.

>Medieval Worlds will thus explore ways to bring together scholars from different disciplines interested in comparable topics, and encourage interdisciplinary groups to publish focused sets of articles.

We are grateful to the Austrian Research Fund (FWF) for providing funds for starting this journal; to the Austrian Academy of Sciences (ÖAW/AAS) and its press for institutional support; and to the whole team of >Medieval Worlds`, including our International Advisory Board, for their help and enthusiasm.

The editors

Walter Pohl and Andre Gingrich 